\title{
Combined use of Risdon Wiring and Lingual Splint in Pediatric Mandibular Fractures
}

\author{
Shadia Abdelhameed Elsayed ${ }^{1,2}$ \\ ${ }^{1}$ Department of Oral and Maxillofacial Surgery, Faculty of Dental Medicine for Girls, Al-Azhar University, Cairo, Egypt \\ ${ }^{2}$ Department of Oral and Maxillofacial Surgery, Taibah University Dental College \& Hospital, Al-Madinah Al-Munawwrah, Saudi Arabia
}

\begin{abstract}
To implement and evaluate a simplified, rapid, single-day emergency management technique for pediatric mandibular fractures, the author applied the current technique of using combined lingual splint with Risdon wiring under sedation anesthesia as a cohort study in a group of pre-school mandibular fracture children aged 4 to 6 years. Clinical outcome variables were fixation length and reduction simplicity, post-reduction occlusion, recovery of mouth opening, and degree of postoperative edema and pain. Age, gender, fracture site and the cause of injury were other study variables. The study involved 11 children suffering from a mandibular fracture in the dental bearing region. The majority of them were males with a proportion of $72.7 \%$. The clinical results obtained from the combined technique were promising in terms of rapid surgical duration, simplicity of fracture reduction, decreased postoperative pain and edema, rapid recovery of mouth opening without a recorded complication. It could be concluded that combining Risdon wiring with lingual splint is a simple, fast, and reliable fixation technique for managing preschool mandibular pediatric fractures.
\end{abstract}

Key Words: Lingual splint, Pediatric, Mandibular, Fracture.

How to cite this article: Elsayed SA. Combined use of Risdon Wiring and Lingual Splint in Pediatric Mandibular Fractures. J Coll Physicians Surg Pak 2021; 31(01):89-91.

\section{INTRODUCTION}

Pediatricmandibularfractures beforetheage of 6 yearsareconsidered to be routine practice for oral and maxillofacial surgeons by the Emergency Department. ${ }^{1,2}$ In most of these cases, the etiology of this injury is due to a fall, followed by vehicular accidents. ${ }^{1,3}$ Due to the critical age span and the anatomical convexity of the restricted undercut bulbous cervical area of deciduous teeth and the very wide open contact region at the deciduous molar sites, it is most difficult to fix an arch bar or to use ordinary ivy loops to reduce the segment and to wire this tooth-bearing area. ${ }^{4}$

In the past, the typical care technique for these forms of trauma was a split acrylic splint mono-fixing approach in combination with circum-mandibular wiring. This procedure was normally done under general anaesthesia with aggressive positioning of further circum-mandibular wiring, which was later to be removed under general anaesthesia in another painful postoperative visit. $^{5}$

Correspondence to: Dr. Shadia Abdelhameed Elsayed, Department of Oral and Maxillofacial Surgery, Faculty of Dental Medicine for Girls, Al-Azhar University, Cairo, Egypt

E-mail: shadiaelsayed25@gmail.com

Received: February 11, 2020; Revised: September 30, 2020; Accepted: December 10, 2020

DOI: https://doi.org/10.29271/jcpsp.2021.01.89
Furthermore, this splint did not ensure a complete three-dimensional reduction or enhance the intimate contact between the fracture segments, especially from the lingual side. ${ }^{6,7}$

At this stage, a lingual step was usually generated by a direct encroachment of the genioglossus and geniohyoid muscles, which prevented the segment from passively positioning to the split acrylic splint, which was stabilised in a higher position and only reduced the teeth in place withoutsecuring the lingual cortex. ${ }^{8,9}$

Risdon cables or wiring were formerly used and described by an otolaryngologist in 1938 in order to address the difficulty of fixing the arch bar above the deciduous teeth. Other methods are usually used as cap splints, computerised engineered splints, wing splints and stainless steel basket splints. Some clinicians tend to use other means of fixations such as resorbable plates for mandibular fractures in young children, but they are costly and technically charged. ${ }^{10}$

The goal of the present study was to introduce the combined use of Risdon wiring and lingual splint in the treatment of pre-school pediatric mandibular fractures as a simplified, rapid, single-day emergency managementtechnique.

\section{METHODOLOGY}

This retrospective cohort study was performed at Al-Azhar University Hospital in Cairo, Egypt between 2011 and 2019. The research was accepted and performed in compliance with the declaration of the Helsinki guidelines by Al-Azhar University Ethical Committee. The data was derived from patient reports 
and operation records. These single-day case procedures were conducted under conscious sedation anesthesia.

The preoperative dental cast was made from a simple alginate impression. At the fracture site, cast fracturing was carried out and reduction of the fracture segments to the proper Pre-fractured location was achieved (Figure 1A). The manufacture of the lingual splint using self-cure acrylic resin was prepared in no more than half an hour in the laboratory on a reduced plaster of Paris cast, then sterilised and packed as standard (Figure 1B).

Fracture segments were reduced using Risdon wire that was secured on the buccal side of the mandibular teeth. A prestretched 0.5 soft stainless steel wire, $25 \mathrm{~cm}$ long, was secured on both sides around the mandibular last molar; and then both ends were twisted together along the buccal side until the midline, then, after cutting off the excess wire, they were grasped together, twisted and tucked in the interdental space (Figure 1C).

For each pre-prepared interdental splint hole, the fixation of the lingual splint with separate wiring was kept in between the teeth contacts and secured anteriorly on the Risdon arch-wire. No other maxillomandibular fixation means have been used in the presentcases(Figure 1D).

The children remained for just one day (single day surgery) and then discharged. Postoperative instructions were given to the parents. After one week, follow-up appointments were planned, then patients were recalled for splint and wire removal after two weeks.

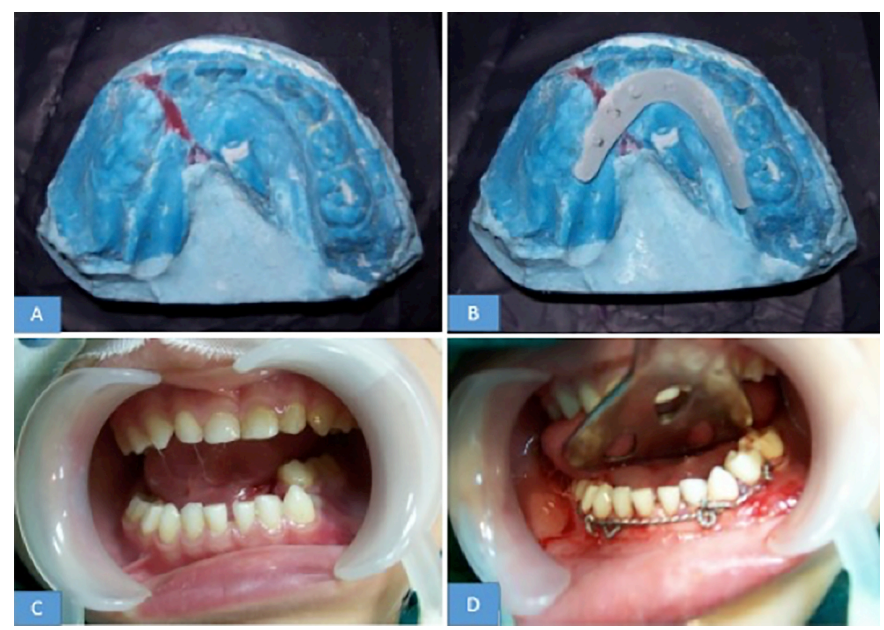

Figure 1: (A) Preoperative dental cast laboratory photograph showing the displaced fracture segments splinted at the fracture site to the proper pre-fractured position after reduction of the fracture segments, (B) Laboratory photograph demonstrating the manufacture of a lingual splint using self-curing acrylic resin, (C) Clinical photograph showing a 5year boy suffering from parasymphysial fracture of the left side, caused by a motorcycle accident. (D) Intraoperative photograph of a reduced fracture segment by means of anteriorly secured Risdon wire and a lingual splint fixation with separate wires held between the teeth and secured to the Risdon arch wire.

\section{RESULTS}

The technique was performed under sedation anaesthesia to eleven children (eight males and three females) with a mean age of 5 years and one month. They were suffering from mandibular fractures. In seven (63.6 percent) cases, the main cause of injury was a fall. Male patients were predominant with a percentage of $72.7 \%$ (Table I). The main fracture site indicated for the combined technique used in this study was tooth bearing areas, which included symphysis, parasymphysis and body region.

Table I: Descriptive demographic data obtained from the children managed with lingual splint-Risdon wiring combined technique.

\begin{tabular}{|c|c|c|c|c|}
\hline Age & Gender & Cause & Fracture site & $\begin{array}{l}\text { Associated } \\
\text { injury }\end{array}$ \\
\hline 5 & Male & Fall & Body & No \\
\hline 5.5 & Male & Fall & Parasymphyseal & No \\
\hline 4.8 & Female & Motorcycle & Symphyseal & $\begin{array}{l}\text { Bilateral } \\
\text { condyle }\end{array}$ \\
\hline 5 & Male & Fall & Symphyseal & $\begin{array}{l}\text { Unilateral } \\
\text { condyle }\end{array}$ \\
\hline 6 & Male & Accident & Parasymphyseal & No \\
\hline 4 & Female & Fall & Parasymphyseal & $\begin{array}{l}\text { Unilateral } \\
\text { condyle }\end{array}$ \\
\hline 4.5 & Female & $\begin{array}{l}\text { Donkey } \\
\text { kicky }\end{array}$ & Body & No \\
\hline 5 & Male & Fall & Symphyseal & No \\
\hline 5.5 & Male & Accident & Parasymphyseal & No \\
\hline 5.9 & Male & Fall & Symphyseal & $\begin{array}{l}\text { Bilateral } \\
\text { condyle }\end{array}$ \\
\hline 5 & Male & Fall & Parasymphyseal & No \\
\hline
\end{tabular}

Splint and wire removal were performed under local aneasthesis after 14 days and no sedation or general aneasthesis was required. With the use of the current combined technique, there were reduction in pain, edema, and rapid regaining of mouth opening in all included cases. There was no postoperative complication reported and all children's occlusion was returned to normal within the first two weeks post fixation.

\section{DISCUSSION}

In the current case study, a combined simpler alternative technique has been implemented that has shown acceptable results and eliminates the need for more aggressive circum-mandibular wiring removal after healing.

At this pre-school age, the only erupting permanent tooth is the first molar, whilethe remaining anterior arch is occupied by deciduous teeth. In this case, if the patient suffers from a fracture in the tooth-bearing areas of the mandible, it might be impractical to fix the arch bar or ivy loops or use ordinary maxillomandibular fixation (MMF) technique..$^{2,11}$

In this specific age group, the present study highly recommends the following rapid one-day management technique that could be performed under sedation anaesthesia without the need for adjunctive circum-mandibular wiring, which is normally performed under general anaesthesia with associated possible hazards, ${ }^{12}$ and is considered to be more aggressive than the combined use of lingual splint and Risdon wiring. With the aid of this simple manual conservative technique, a three-dimensional reduction of the fracture can be achieved with a strong fixation method. ${ }^{2,8,10}$ 
Further studies should concentrate on using a more simplified technique that can be conducted under local anesthesia without the need for impression taking and without laboratory work. All preparations could be performed in future via computerised virtual planning and 4D printing technology or remote operative fixation via robots.

\section{CONCLUSION}

This study suggests that the combined use of Risdon wiring with lingual splint is a rapid, simple, reliable technique for the managing pre-school mandibular pediatric fractures that are less invasive than the other available circum-mandibular wiring required for traditional split acrylic or cap splints.

\section{CONFLICT OF INTEREST:}

The author declared no conflict of interest.

\section{AUTHOR'S CONTRIBUTION:}

SAE: Reviewed, designed, edited the manuscript and approved the final submitted manuscript.

\section{REFERENCES}

1. Elsayed SA, Khalifa F, Khalifa El-Sayed A, Altaweel AA. Different osteosynthesis devices used in fixation of anterior mandibular fracture: Review article. J Dent Maxillofac Res 2018; 2(2):60-4. DOI: 10.30881/ jdsomr.00031.

2. Lee JW, Choi BJ, Nam OH, Kwon YD. Minimal invasive treatment using patient-specific template for mandibular fractures in children: "Wing-splint" by CAD/CAM technology. Br J Oral Maxillofac Surg 2016; 54(10): 1140-1. doi.org/10.1016/j.bjoms.2016.03.024.

3. Wolfswinkel EM, Weathers WM, Wirthlin JO, Monson LA, Hollier LH, Khechoyan DY. Management of pediatric mandible fractures. Otolaryngol Clin North Am 2013; 46(5):791-806. doi.org/10.1016/j.otc.2013.06.007.
4. Thomas S, Yuvaraj V. Atraumatic placement of circummandibular wires: A technical note. Int J Oral Maxillofac Surg 2010; 39(1):83-5. doi: 10.1016/j.ijom. 2009.06.029.

5. Elsayed SA. Unusual pattern of mandibular fracture displacement in a child: A case report. J Taibah Univ Med Sci 2017; 12(2):174-7. doi: 10.1016/j.jtumed.2016. 12.008.

6. Elsayed SAH, Elsayed EH, Altaweel AA. Stabilisation of anterior mandibular fracture using different osteosynthesis devices: Perioperative clinical notes. Oral Maxillofac Surg 2020; doi.org/10.1007/s10006-02000917-9.

7. Elsayed SA. Uses of cortical screw lag fixation technique in the management of mandibular injuries. Clinical experience and tricks. J Korean Assoc Oral Maxillofac Surg 2020; 46(5): 299-370.

8. Kushner GM, Tiwana PS. Fractures of the Growing Mandible. Atlas Oral Maxillofac Surg Clin North Am 2009; 17(1):81-91. doi.org/10.1016/j.cxom.2008.11.001.

9. Li Z, David O, Li ZB. The use of resorbable plates in association with dental arch stabilisation in the treatment of mandibular fractures in children. J Cranio-Maxillofacial Surg 2014; 42(5):548-51. doi.org/10.1016/j.jcms.2013. 07.025 .

10. An J, Jia $P$, Zhang $Y$, Gong $X$, Han $X$, He $Y$. Application of biodegradable plates for treating pediatric mandibular fractures. J Cranio-Maxillofacial Surg 2015; 43(4):515-20. doi.org/10.1016/j.jcms.2015.03.002.

11. Chiu GA, Prabhu IS, Morton ME, Carmichael GJ. Acrylated stainless steel basket splint for mandibular fractures in children. Br J Oral Maxillofac Surg 2012; 50(6):577-8. doi.org/10.1016/j.bjoms.2011.12.004.

12. Elsayed SA, Mohamed FI, Khalifa GA. Clinical outcomes of three different types of hardware for the treatment of mandibular angle fractures: A comparative retrospective study. Int J Oral Maxillofac Surg 2015; 44(10):1260-7. 